\title{
Study on Electro-hydraulic Servo Valve Control System of Series Manipulator
}

\author{
Zhang Daode ${ }^{1}$, Yan Pian ${ }^{2}$, Wang Zhouxing ${ }^{3}$ and Wu Yuan ${ }^{4}$ \\ Engineering Research Center of Wuhan Light Industry Equipment, School of \\ Mechanical Engineering, Hubei University of Technology \\ E-mail: hgzdd@126.com;348868533@qq.com
}

\begin{abstract}
This article introduces the composition and principal of servo valve asymmetric hydraulic cylinder position control system, valve controlled asymmetric cylinder system model is set up in the AMESim(Advanced Modeling Environment for performing Simulation of engineering systems), in the form of s-function is imported into PID(Proportion Integration Differentiation) control system model of Simulink for simulation analysis of AMESim and Simulink; Design the Fuzzy PID controller, Comparison the curves of the dynamic characteristics of the system with traditional PID and Fuzzy PID controller, the experimental results show that the system model design is reasonable, after joining PID control, system has faster response speed, stability and high precision.
\end{abstract}

Keywords: Series mechanical arm AMESim /Simulation Electro-hydraulic servo valve Fuzzy PID control

\section{Introduction}

Hydraulic mechanical arm control system [1] is a typical integration structure of mechanical, electrical and hydraulic, hydraulic valve control system [2] is the core part that controls the dynamic response characteristics of system, which is an important indicator for measurement and calibration of design and debugging level of a set of hydraulic system. The electro-hydraulic servo valve is relatively mature and widely used in engineering of this system, but its most obvious characteristic is the character of nonlinear and hard to be set up the control model. At the same time, for the existence of outside interference of complex external working environment, highly working frequency and tracking accuracy of control object is usually required for electro-hydraulic servo system [3].

Therefore, in this paper, through the study of the performance in characteristic curve analysis and calculation of the transfer function for electro-hydraulic servo valve, emulate and draw the bode diagram to verify whether the servo valve control system is stable [4]. For convenience of hydraulic servo system to achieve better control effect in the practical application, more and more intelligent control technology has been applied in the field of electric hydraulic servo control [5], the fuzzy PID has the characteristics of self-learning and adaptive ability, it can adapt to the environmental changes, has the strong robustness, and very applicable for the electro-hydraulic servo system with the characteristics of large disturbance, time-varying parameters, wide operating range and accurate mode hard.

So, in this system, this article uses the fuzzy PID control algorithm [6-7], and compared with the conventional control algorithm. At first in this paper, the hydraulic servo valve system and control model are set up in AMESim [8] platform only, which is not intuitive and modeling difficulty, but the Simulink platform of Matlab [9] is a visual simulation tools, and widely used in linear systems, nonlinear systems, digital control and digital signal processing (DSP) for modeling and simulation. Therefore, according to the 
requirements of the subject and the advantages of each other, we select the AMESim platform to build a hydraulic system model, and the establishment of a control system model under Matlab platform [10].

\section{Introduction of the Simulation Environment}

AMESim software is a integrates advanced engineering system software of simulation and modeling which set fluid, liquid, gas, machinery, control, electromagnetic and other areas at an organic whole, it is facilitate for modeling and while also allowing designers to modify and optimize the system solutions in the process of simulation optimization; Co-simulation [11] is building the hydraulic part model structures under AMESim simulation environment in accordance with the actual physical system, obtaining $\mathrm{s}$ function under Simulink environment, via the interface function module to import the sfunction into control system model, and then complete the establishment of system control part model under Matlab/Simulink platform, then compiling and running the system, basis on the graphics for data analysis and design optimization.

Co-simulation of the AMESim/Simulink [12] is using the convenient and intuitive of AMESim software to build physical modeling simulation, which is better for optimization design of system, getting rid of the cumbersome process of programming, at the same time, combining with the functions of excellent data processing and graphic export, with programming control and algorithm optimization of Simulink, modeling in their respective professional software environment respectively, for the whole system's co-simulation and optimization research through the interface between each other.

\section{Hydraulic Valve Control System Model under AMESim/Simulink Environment}

Control object of hydraulic valve control system is asymmetric hydraulic cylinder stroke that is the location of the terminal operator; The whole system is divided into power part, control part and actuators, including single-acting quantitative pump, electro-hydraulic servo valve, asymmetric hydraulic cylinder and load. With current as input, flow as output, specific parameters such as Table 1:

Table 1. Parameters Set

\begin{tabular}{|lc|ll|}
\hline Component parameter & Numerical & Component parameter & Numerical \\
\hline Hydraulic cylinder CylinderD1/mm & $80 \mathrm{~mm}$ & Servo valve model & D633 \\
\hline Hydraulic cylinder bore d1/mm & $63 \mathrm{~mm}$ & Valve Specification & $\begin{array}{l}\text { Three-position } \\
\text { four-way valve }\end{array}$ \\
\hline Cylinder pistonD2/mm & & & \\
\hline Piston stroke s/m & $45 \mathrm{~mm}$ & Valve port diameterD3/mm & $7.9 \mathrm{~mm}$ \\
\hline Mass m/kg & $0.8 \mathrm{~m}$ & Maximum flow Q/(L/min) & $75 \mathrm{~L} / \mathrm{min}$ \\
\hline Artificial load F/KN & $0.3 \mathrm{~kg}$ & Input current $\mathrm{I} / \mathrm{mA}$ & $40 \mathrm{~mA}$ \\
\hline Valve pressure drop P/MP & $20 \mathrm{KN}$ & Frequency $\mathrm{w} / \mathrm{Hz}$ & $80 \mathrm{~Hz}$ \\
\hline
\end{tabular}

\subsection{Hydraulic Cylinder - Load Function}

Due to the existence of hydraulic system flow, pressure loss and other complex influence factors, it can be assumed that, valves and hydraulic cylinder connecting pipes are symmetrical and short, therefore, the complex dynamic characteristics and the pressure loss of the pipes can be ignored; At the same time, the working chamber pressure of asymmetric hydraulic cylinder are equal throughout, the temperature and the elastic modulus are constant. 
By determining the continuity equation of servo valve flow and the continuity equation of hydraulic cylinder flow and the balance equation of force to get the transfer function of hydraulic cylinder piston load:

$$
\frac{X_{P}}{Q_{L}}=\frac{\frac{1}{A_{P}}}{S\left(\frac{S^{2}}{W_{\mathrm{h}}^{2}}+\frac{2 \zeta_{h}}{W_{h}} S+1\right)}
$$

Where:

$X_{P}$ — Displacement of hydraulic cylinder piston;

$Q_{L}$ - Flow of load;

$A_{p}$ _ Effective working area of hydraulic cylinder;

$W_{h}$ - Natural frequency of Hydraulic;

$\zeta_{h}$ - Damping ratio.

Where:

Effective working area of hydraulic cylinder is:

$$
A_{P}=\frac{\pi}{4}\left(D^{2}-d^{2}\right)=\frac{\pi}{4}\left(6.3^{2}-4.5^{2}\right)=15.3 \mathrm{~cm}^{2} ;
$$

Natural frequency:

$$
\begin{aligned}
W_{h} & =\sqrt{\frac{4 \beta_{\mathrm{e}} A_{p}^{2}}{V_{t} M_{t}}}=\sqrt{\frac{4 \times 1.0^{6} \times\left(15.3 \times 10^{-4}\right)^{2}}{989.3 \times 10^{-6} \times 0.3}} \\
& =176.7 \mathrm{rad} / \mathrm{s}=28.2 \mathrm{HZ} ;
\end{aligned}
$$

According to system requirements, we take 0.8 as the damping ratio $\zeta_{h}$ of hydraulic;

Substituting the dates that we can get the transfer function of hydraulic cylinder load as follows:

$$
\frac{X_{\mathrm{P}}}{Q_{\mathrm{L}}}=\frac{\frac{1}{A_{p}}}{\mathrm{~S}\left(\frac{s^{2}}{W_{h}^{2}}+\frac{2 \zeta_{h}}{W_{h}} S+1\right)}=\frac{\frac{1}{15.3 \times 10^{4}}}{\mathrm{~S}\left(\frac{s^{2}}{176.7^{2}}+\frac{2 \times 0.8}{176.7} s+1\right)}=\frac{0.07 \times 10^{-4}}{S\left(\frac{s^{2}}{176.7^{2}+0.01 s+1}\right)}
$$

\subsection{Transfer Function of Servo Valve}

D633 servo valve which with low leakage, low power consumption and high dynamic response, suitable for multi valve control system, when the power failure or cable damage or emergency stop working, the valve back will be in place to make the load in a safe state, therefore it is suitable for the research object.

So, in this system, we chose D633 servo valve, according to the electromagnetic torque motor, the feedback of force - displacement, the flow continuity and force balance equation of valve core to derive the transfer function formula:

$$
\mathrm{G}_{\mathrm{sv}}(\mathrm{s})=\frac{\mathrm{Q}_{0}(\mathrm{~s})}{\mathrm{I}(\mathrm{s})}=\frac{\mathrm{K}_{\mathrm{sv}}}{\frac{\mathrm{s}^{2}}{\mathrm{w}_{\mathrm{sv}}^{2}}+\frac{2 \zeta_{\mathrm{sv}}}{\mathrm{w}_{\mathrm{sv}}} \mathrm{s}+1}
$$

Where:

$$
\begin{aligned}
& Q_{0}(s) \text { - Laplace transform of Light load flow change; } \\
& I(\mathrm{~s}) \text { - Laplace transforms of the input current change; }
\end{aligned}
$$


$W_{S V}$ - Natural frequency of servo valve;

$\zeta_{S V}$ - Damping ratio;

$K_{S V}$ - Servo valve flow gain, according to the valve flow characteristic curve, check the valve pressure drop table, when $p_{s}$ values $5.6 \mathrm{MPa}$, rated flow values $38 \mathrm{~L} / \mathrm{min}$, known $I_{n}$ is $0.04 \mathrm{~A}$, rated flow Values $40 \mathrm{~L} / \mathrm{min}$, so when the actual fuel supply $5.6 \mathrm{MPa}$ that flow gain of valve gets:

$$
K_{s V}=q_{n} \frac{\sqrt{\frac{p_{s}}{p_{s V}}}}{I_{n}}=40 \times 10^{-3} \frac{\sqrt{5.6 / 7}}{60 \times 0.04}=0.014 \mathrm{~m}^{3} /(\mathrm{S} \cdot \mathrm{A})
$$

According to the frequency response characteristic curve of the D633 servo valve, we get the frequency values when Root amplitude ratio is $-3 \mathrm{~dB}$ (Output flow is $70.7 \%$ of the Output flow rate of reference frequency) as the value of ${ }^{W_{S V}}$ is:

$$
W_{S V}=62 \times 2 \pi=389.36 \mathrm{rad} / \mathrm{s}=62 \mathrm{~Hz} ;
$$

According to the formula:

$$
\psi(W)=\operatorname{arctg} \frac{2 \zeta_{S V} \frac{S V}{W S V}}{1-\left(\frac{W}{W_{W V}}\right)^{2}} ;
$$

It can take the value of ${ }^{\psi(W)}$ as $-40^{\circ},-45^{\circ}$ and $-50^{\circ}$, respectively calculate the values of $\zeta_{S V}$ and then take average number of the three values, it will get the value of $\zeta_{S V}$ is 0.72 . Thus:

$$
\begin{aligned}
G_{\mathrm{sv}}(s) & =\frac{\mathrm{K}_{\mathrm{sv}}}{\frac{\mathrm{s}^{2}}{\mathrm{~W}_{\mathrm{sv}}^{2}}+\frac{2 \zeta_{\mathrm{sv}}}{\mathrm{w}_{\mathrm{sv}}} \mathrm{s}+1}=\frac{0.014}{\frac{s^{2}}{389.36^{2}}+\frac{2 \times 0.72}{389.36} s+1} \\
& =\frac{0.014}{\frac{s^{2}}{1.5 \times 10^{5}}+0.004 s+1}
\end{aligned}
$$

\subsection{The Open-Loop Potter Map of System}

In summary, the transfer function of the system is:

$$
\begin{aligned}
H(s) K(f) & =\frac{X_{P}}{Q_{L}} \frac{Q_{0}(s)}{I(s)} K_{a} K_{f} \\
& =\frac{0.98 \times 10^{-7} K_{a} K_{f}}{s\left(\frac{s^{2}}{176.7^{2}+0.01 s+1}\right)\left(\frac{s^{2}}{1.5 \times 10^{5}}+0.004 s+1\right)}
\end{aligned}
$$

$K_{a}$ - Gain of Servo valve amplifier, value of system is 1 ;

$K_{f}$ — Gain of Displacement sensor, values 10;

Drawing Bode diagram of the transfer function under MATLAB environment, as shown in Figure 1: 


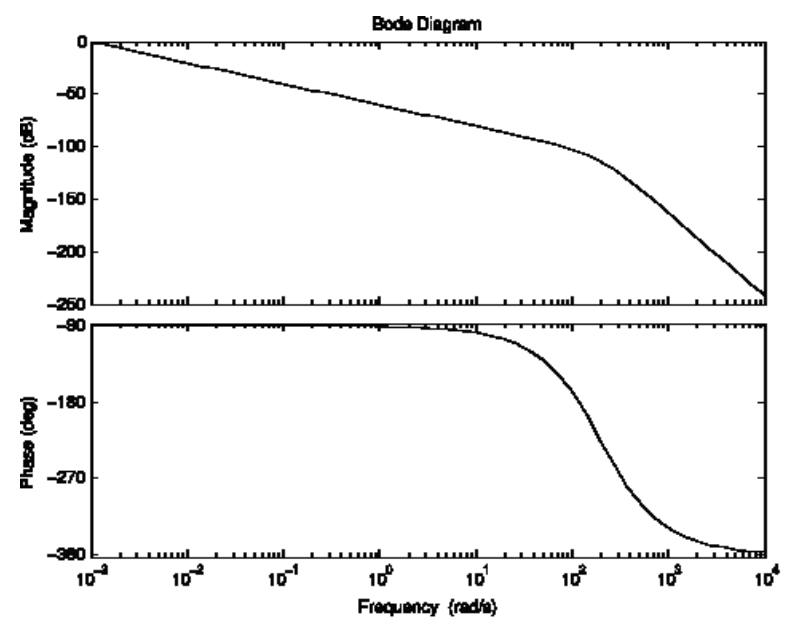

Figure 1. Open Loop Bode Diagram of Servo System

The Bode diagram characteristic curve of system shows that the hydraulic servo system is stable and meeting the requirements for the operation under the given conditions, but the setting of the system parameters are on the basis of ignoring the conditions of external interference and ideal equipment, which is without considering the factors such as nonlinear, perturbation and time-varying parameters of the servo valve and so on, while actually, the factors of nonlinear must be taken into account, so this paper adding fuzzy PID controller into this system, the whole hydraulic system schematic diagram as shown in Figure 2:

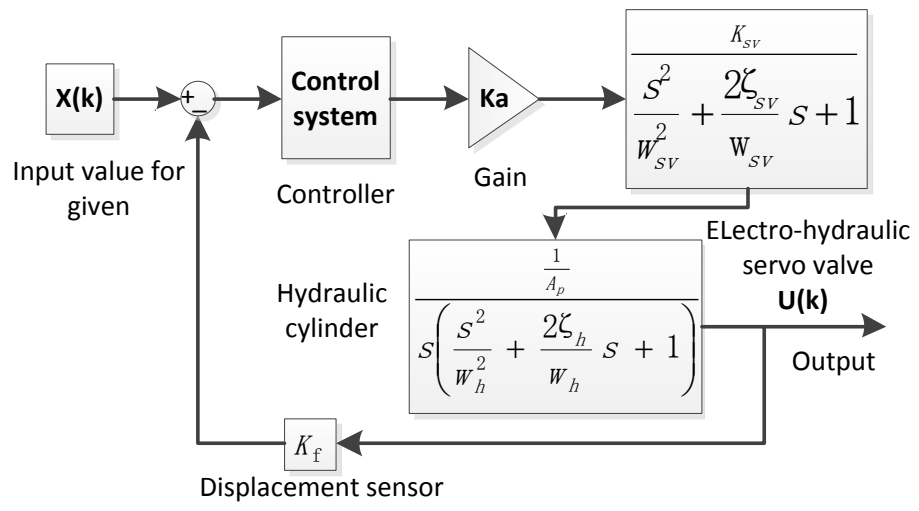

Figure 2. Schematic Diagram of Electro Hydraulic Servo System

AMESim simulation software is based on power bond graph, simple and intuitive physical model can liberate operator from the tedious mathematical model that to focus on the design of the physical system itself, therefore, according to the actual engineering design principle diagram of the system, it can be quickly set up the system model by using Mechanical library, Hydraulic library and Signal and Control library under the AMESim environment, the system model as shown in Figure 3. 


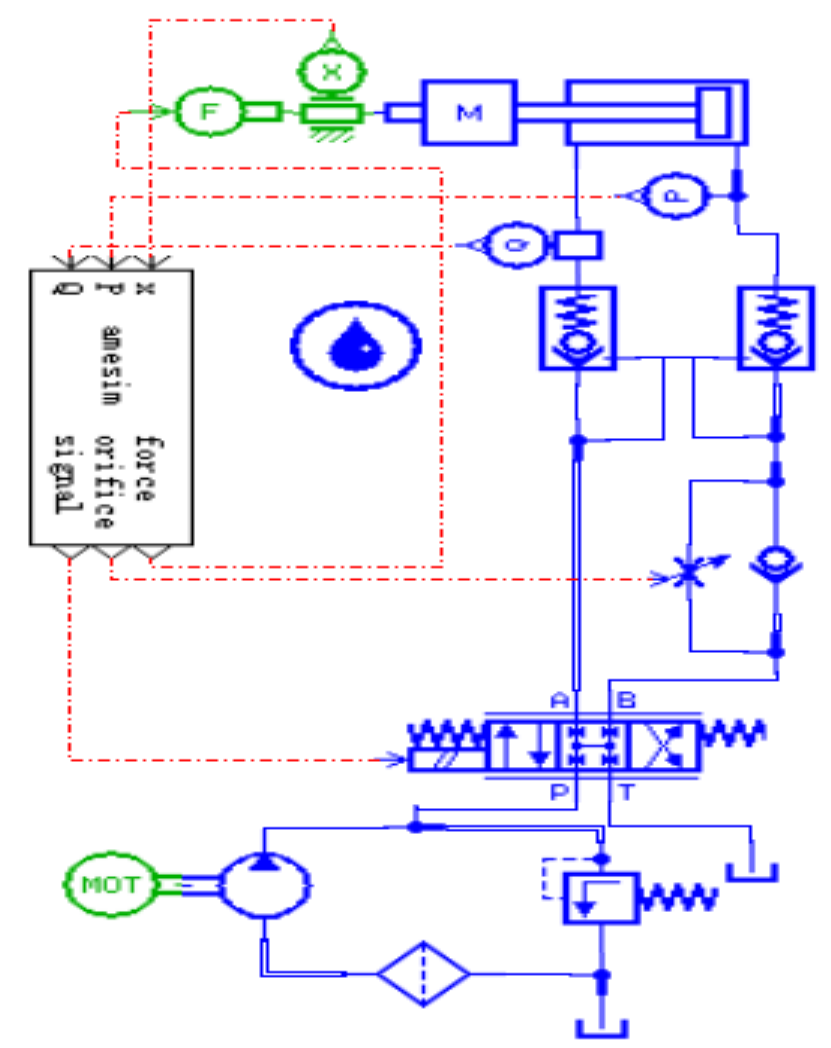

\section{Figure 3. Schematic Diagram of Electro Hydraulic Servo System under AMESim Environment}

The gain value is 10 , the time displacement of a given signal source is $0.5 \mathrm{~m}$, and the other parameters are default.

This system is used to complete the pitch homework of the hydraulic mechanical arm [13]; it is mainly composed of the hydraulic cylinder, hydraulic control one-way valve, throttle valve, electric hydraulic servo valve, relief valve, one-way valve, quantitative pump, oil filter, signal source and gain etc. And it is a typical negative feedback closed-loop control system.

Artificial load presets a set of actual load value to the system, and the displacement sensor [14] converts the actual output displacement of the actuator into electrical signals, and then exports the deviation signal of displacement which is obtained by comparing the electrical signal with the targets value of the system, makes the output signal which is obtained via gain structure by magnifying the deviation signal that as current input signal of servo valve to control the connect or cut off of the actuator's supple of hydraulic oil and change the direction of oil supply, via the change of hydraulic flow of output to achieve control of the displacement magnitude and direction of actuator.

As long as the deviation between displacement of output and the given displacement execution mechanism is given, the system can automatically adjust the displacement of output until it reach the range of allowable error.

In this case, it is using hydraulic controlled check valve as the interlock circuit of the hydraulic cylinder, and throttle valve to adjust the return speed of the hydraulic cylinder.

\section{4 .Design and Simulation of Control System}

\subsection{Design of Fuzzy PID Controller}

The number of input variable of fuzzy controller is called the dimensions of the fuzzy controller, this system uses two dimensional fuzzy controller, compared with one 
dimension and three dimension fuzzy controller, it is more practical; The language variable of input are controlled quantity and the given value of deviation e and deviation change rate ${ }^{e_{c}}$, modified $\mathrm{Kp}, \mathrm{Kd}, \mathrm{Ki}$ as the output of the adaptive fuzzy PID controller.

Schematic diagram as shown in Figure 4:

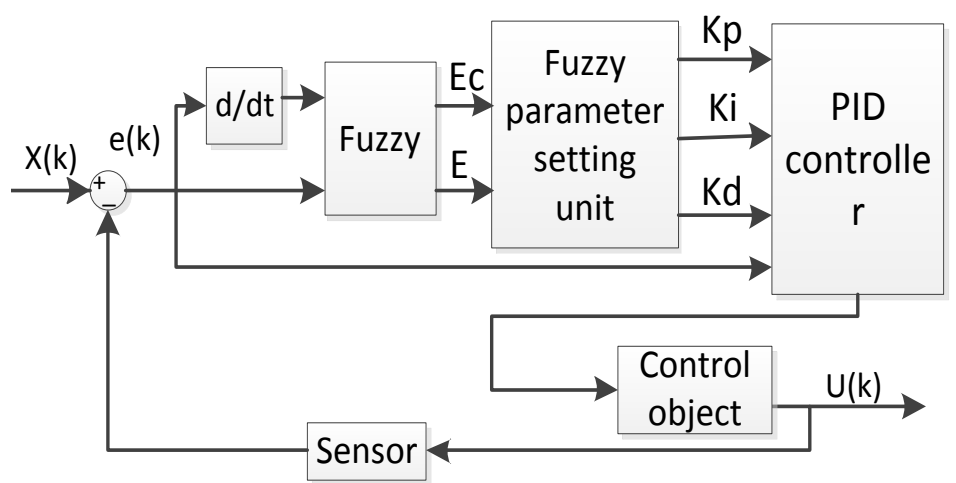

Figure 4. Principle Diagram of Adaptive Fuzzy PID Control

Using the PID control of position type, the expression after discretion is:

$$
u(k)=K_{P} e(k)+K_{\mathrm{i}} \sum_{j=0}^{k} e(j)+K_{d}(e(k)-e(k-1))
$$

$u(k)$ - Computer output value of the $\mathrm{k}$ times of sampling time;

$e(k)$ _ Deviation value of input of the $\mathrm{k}$ times of the sampling time;

$e(k-1)$

- Deviation value of input of the (k-1) times of the sampling time;

$K_{i}$ - Integral coefficien, $K_{i}=K_{p} T / T_{\text {i }}$;

$K_{d}$ - Differential coefficient, $K_{d}=K_{p} T_{d} / T$;

Matlab Fuzzy Control Toolbox provides a very convenient way for the design of fuzzy controller. We do not need to carry out complex fuzzy, fuzzy reasoning and anti-mode, and only need to set the corresponding parameters, we can get the control device we need quickly, and it is very convenient.

In this paper, we use fuzzy toolbox of Matlab to construct fuzzy inference system and select the theory domain of input and output basis on the actual situation. The fuzzy aggregates of the deviation e and the deviation change rate $e_{c}$ is $[-3,-2,-1,0,1,2,3]$; The fuzzy aggregate of the correction parameters are as follows: $\mathrm{Kp}$ is $[0,1,2,3], \mathrm{Ki}$ is $[0,1,2,3], \mathrm{Kd}$ is $[0,1,2,3]$.

The setting of fuzzy linguistic variable as deviation e and deviation change rate $e_{c}$ are as follows: $\{\mathrm{NB}(\mathrm{Ne}-\mathrm{maximum}), \mathrm{NM}(\mathrm{Ne}-$ middle), $\mathrm{NS}(\mathrm{Ne}-\mathrm{minimum}), \mathrm{ZO}(\mathrm{Zero})$, PS(Po-minimum), PM(Po-middle), $\mathrm{PB}$ (Po-maximum)\}; Setting of fuzzy linguistic variable as $\mathrm{Kp}$ are $\{\mathrm{ZO}(\mathrm{Zero}), \mathrm{PS}(\mathrm{Po}-\mathrm{minimum}), \mathrm{PM}($ Po-middle), $\mathrm{PB}($ Po-maximum) $\}$,

and the same as $\mathrm{Ki}$ and $\mathrm{Kd}$; Membership functions of e, ${ }^{e_{c}}$ and $\mathrm{Kp}, \mathrm{Ki}, \mathrm{Kd}$ are the formula of trimf type (Triangle membership function)t that as formula (7), Graphics as shown in Figure 5 and Figure 6: 


$$
\operatorname{trig}(x ; b, c)=\left\{\begin{array}{rc}
0 & x \leq a \\
\frac{x-a}{b-a} & a \leq x \leq b \\
\frac{c-x}{c-b} & b \leq x \leq c \\
0 & c \leq x
\end{array}\right.
$$

According to the different stages with different characteristics of the deviation e and the deviation change rate $e_{c}$, principle of parameter setting of $\mathrm{Kp}, \mathrm{Ki}, \mathrm{Kd}$ are as follows:

1).When the controlled volume is close to the given value, namely, the deviation is relatively small, then appropriate adjustment of the integral role can effectively avoid the overshoot and oscillation, and guarantee the stability; In the same way, when the charged amount is far from the given value, namely, deviation increases, appropriate adjustment of the proportion of the role can effectively control the deviation, but the value of Kp should not be too large, otherwise it will cause overshoot.

2).Early regulation, in order to speed up the response speed and avoid overshoot, we should appropriate to take large value of $\mathrm{Kp}$, and take a small or zero value of $\mathrm{Ki}, \mathrm{Kd}$; Medium term, it can be taking a moderate value of $\mathrm{Kp}$ and fine-tuning the value of $\mathrm{Ki}$ to avoid the overshoot and ensure the stability and control accuracy; Later stage, fine-tuning the value of $\mathrm{Kp}$, appropriate to increase the value of $\mathrm{Ki}$, at the same time, adjust the value of $\mathrm{Kd}$ for eliminate the error and suppress the overshoot.

3).The main function of differential coefficient $\mathrm{Kd}$ is for auxiliary adjustment of $\mathrm{Kp}$ and $\mathrm{Ki}$. It is able to predict the deviations in advance and then restrain the change of the controlled plant, speed up the adjustment and reduce the steady state error.

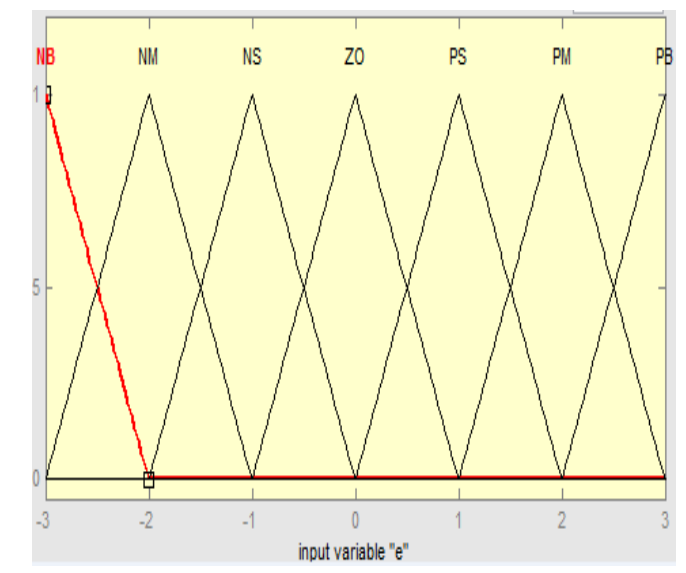

Figure 5. Membership Degree Curve of e, ${ }^{e_{c}}$ Degree Curves 


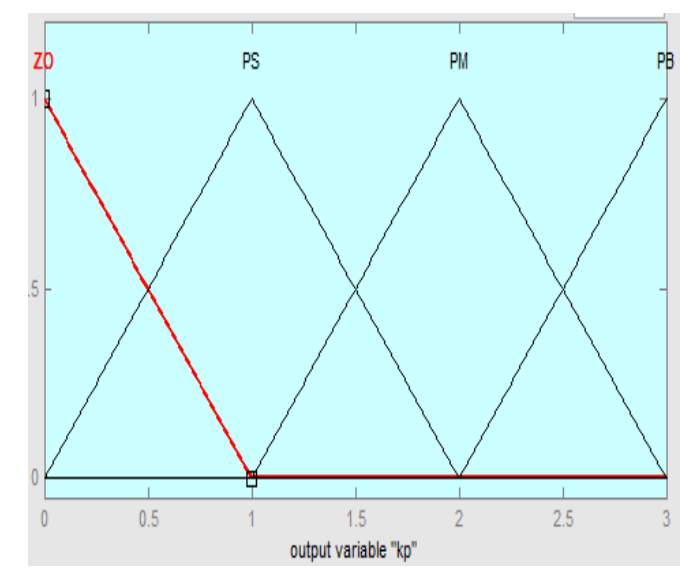

Figure 6. Membership of $\mathrm{Kp}, \mathrm{Ki}$, and $\mathrm{Kd}$

The core of fuzzy control is fuzzy controller, and the fuzzy control rule is the key point to the fuzzy controller, namely, the formulation of fuzzy rule table, therefore, according to the principle of parameters setting above, fuzzy control rules are formulated, as shown in Table 2:

Table 2. Fuzzy Control Rules of Kp, Ki, Kd

\begin{tabular}{|c|c|c|c|c|c|c|c|c|c|}
\hline & \multicolumn{10}{|c|}{ e/ec } \\
\cline { 2 - 9 } & $\begin{array}{c}\mathrm{NM} \\
/ \mathrm{NM}\end{array}$ & $\begin{array}{c}\mathrm{NM} \\
/ \mathrm{PM}\end{array}$ & NS/NS & NS/PS & PS/NS & PS/PS & PM/NM & PM/NM & PB \\
\hline $\begin{array}{c}\mathrm{Kp} / \mathrm{Ki} / \mathrm{Kd} \\
\mathrm{PM} / \mathrm{PS} \\
/ \mathrm{PM}\end{array}$ & $\begin{array}{c}\mathrm{PM} / \mathrm{PS} \\
/ \mathrm{PM}\end{array}$ & $\begin{array}{c}\mathrm{PB} / \mathrm{PB} \\
/ \mathrm{PM}\end{array}$ & $\begin{array}{c}\mathrm{PB} / \mathrm{PB} \\
/ \mathrm{PM}\end{array}$ & $\begin{array}{c}\mathrm{PB} / \mathrm{PB} \\
/ \mathrm{PM}\end{array}$ & $\begin{array}{c}\mathrm{PB} / \mathrm{PB} \\
/ \mathrm{PM}\end{array}$ & $\begin{array}{c}\text { PB/ZO } \\
/ \mathrm{PS}\end{array}$ & $\begin{array}{c}\text { PM/PS } \\
/ \mathrm{PS}\end{array}$ & $\begin{array}{c}\mathrm{PB} / \mathrm{ZO} \\
/ \mathrm{PS}\end{array}$ \\
\hline
\end{tabular}

\subsection{Simulation of Control System}

Finish building the model structures on the basis of system principle diagram of fuzzy PID control system and setting parameter of elements for the control system in Untitled file under the Simulink environment. Fuzzy PID control system will tuning and optimization parameters automatically, in this paper, we set the PID initial values as: $\mathrm{Kp}=1, \mathrm{Ki}=1, \mathrm{Kd}=0$.

In the process of adjusting, quantitative factors $\mathrm{Ke}$ and $\mathrm{Kc}$ have larger impact on the system, increase the value of Ke will decrease the steady-state error which caused by the quantization error, but oversize value will make the system overshoot, with the increase of time, it will cause oscillation of the system; Kc has an obvious containment effect on overshoot, take a larger value, the overshoot of system will be reduced, but the response speed will slow down.

Fuzzy inference system uses Matlab fuzzy toolbox to establish the FIS file of the control system. The conventional control system and the structure of fuzzy toolbox are shown in Figure 7 and 8:

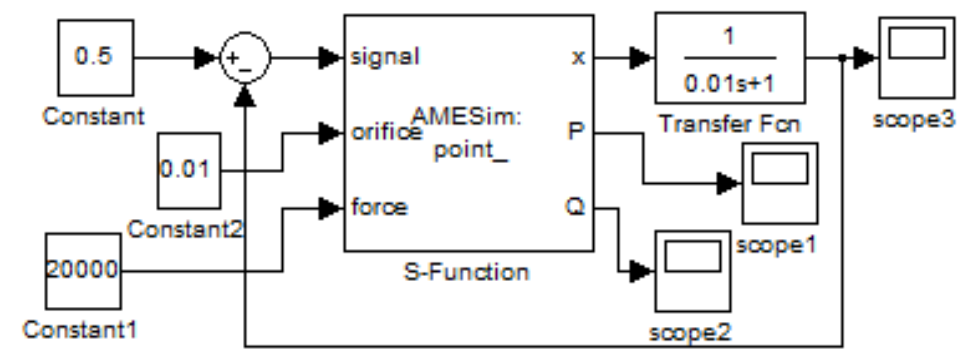




\section{Figure 7. Control Systems Model without PID Control under Simulink Environment}

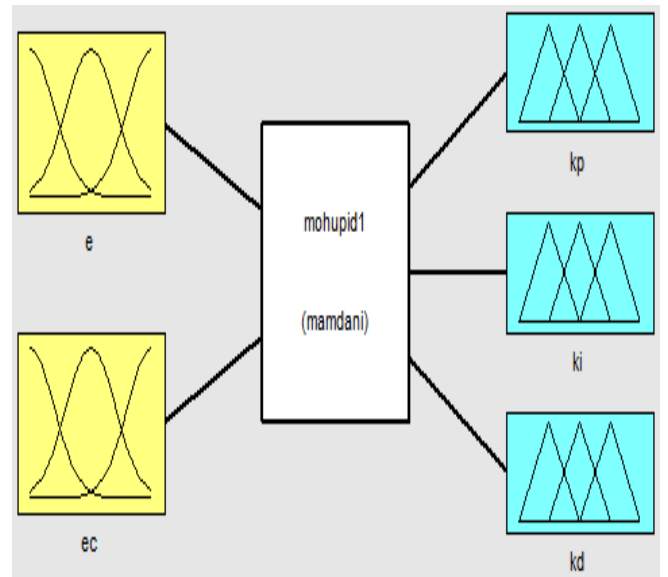

Figure 8. Fuzzy Toolbox Reasoning Structure

By calculation, $\mathrm{Ke}$ is $3.75, \mathrm{Kc}$ is 7.5 . Fuzzy PID control system model as shown in Figure 9

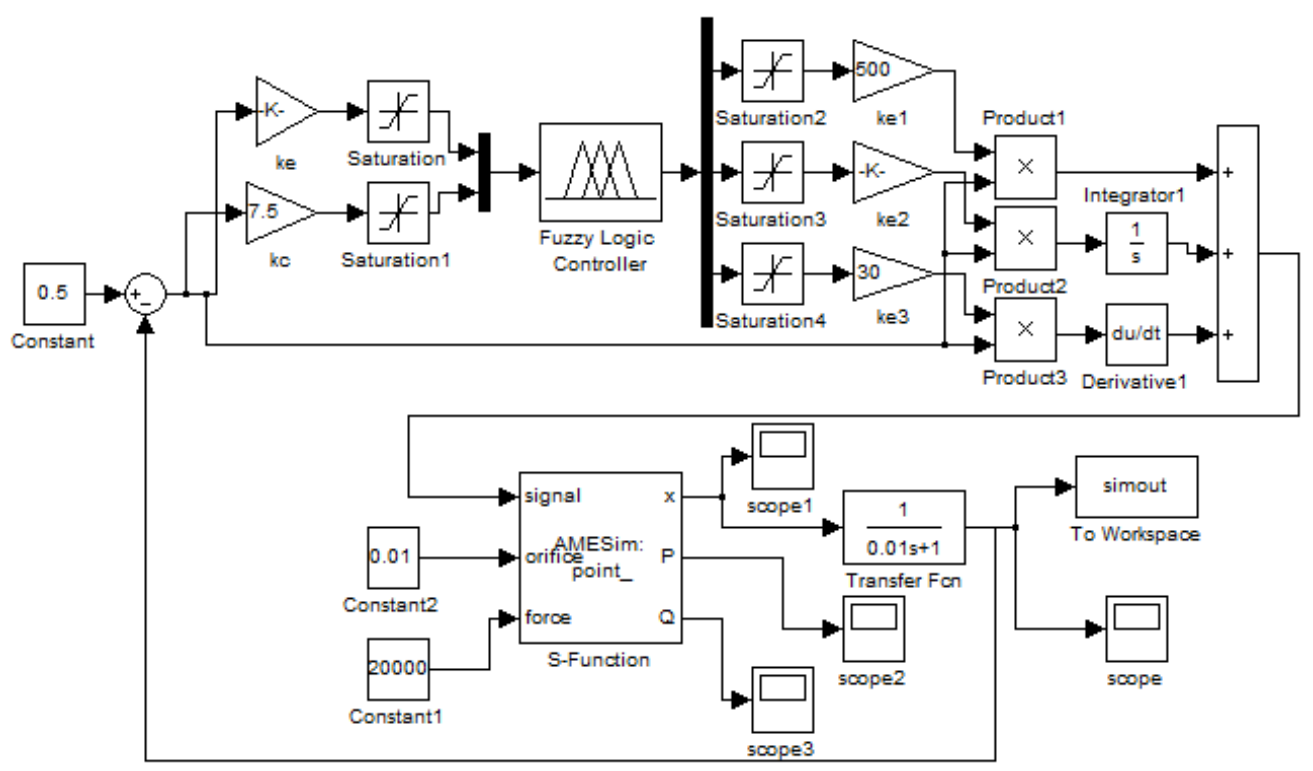

Figure 9. Fuzzy PID Control System Model under Simulink

\subsection{Analysis of Simulation Results}

The main point to text the simulation of this system is going to track and check the output displacement of hydraulic actuating mechanism, and check whether the actuator can follow better and reach the position that required by the manipulator for the given signal of displacement, at the same time, it also need to check that whether the system pressure and flow value can meet the requirements of design, and check the influence of fuzzy PID controller on the response of the whole system, the results of simulation diagram as shown in Figure 10 and Figure 11:

As you can see from the Figure 10, for a given signal, the pressure rising steadily and stabilized at around 5.6MP after a slight jitter occurs in the final position, less than $7 \mathrm{MP}$ 
that the given value of system, and meets the requirements of system; The displacement of actuator can be smoothly and steadily rising and then stable in the desired position that given by the system.

However, it is increasing slowly and the stability time is close to 100 s, although meets the requirements of design, the system response is slowly. After jointing the co-simulation, the affection of fuzzy PID control is obvious, the response speed of displacement speed up significantly and response time stability nearly 20 s, the tracking error of position is less than $0.1 \%$, satisfies the requirement of error, and the system stability is better, no overshoot and oscillation, the results as shown in Figure 11.

The finally optimized parameters are $\mathrm{Kp}=500, \mathrm{Ki}=0.05, \mathrm{Kd}=30$;

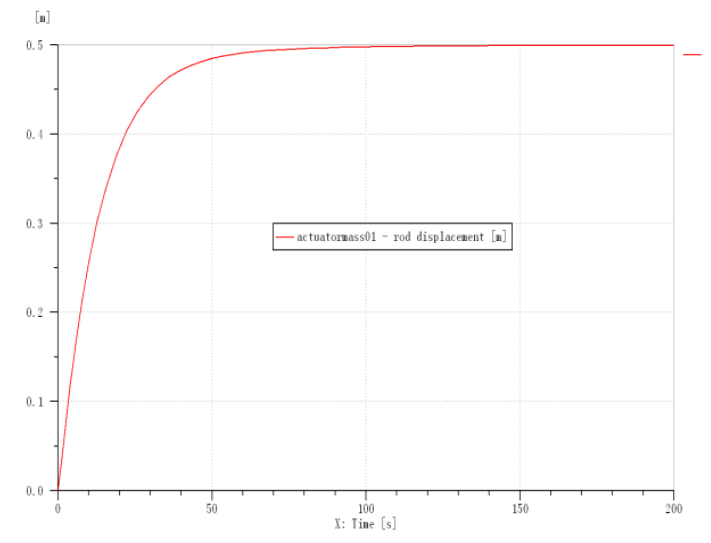

Figure 10 (a). Output Displacement of Actuator without PID Control

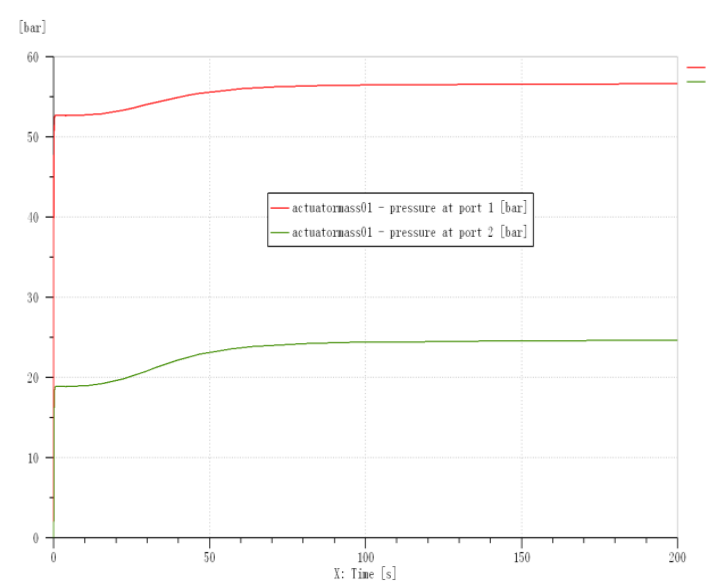

Figure 10 (b). Output Pressure of Actuator without PID Controls 


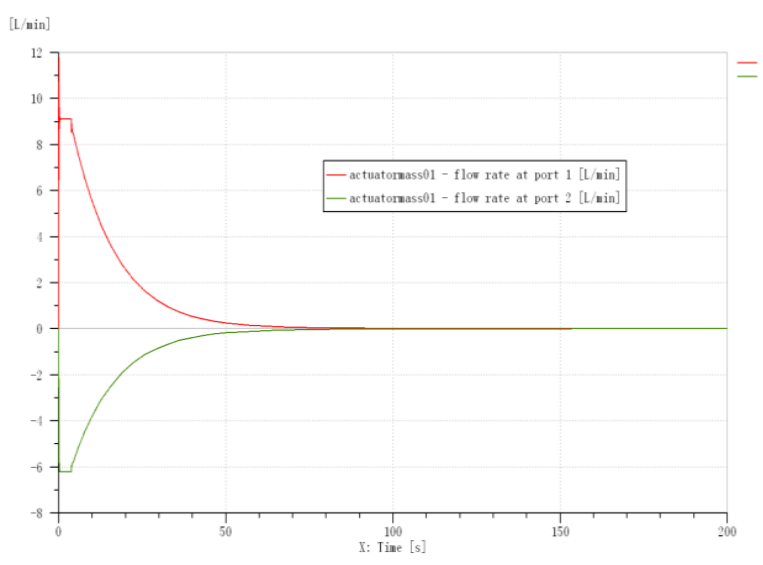

Figure 10 (c). Output Flow of Actuator without PID Control

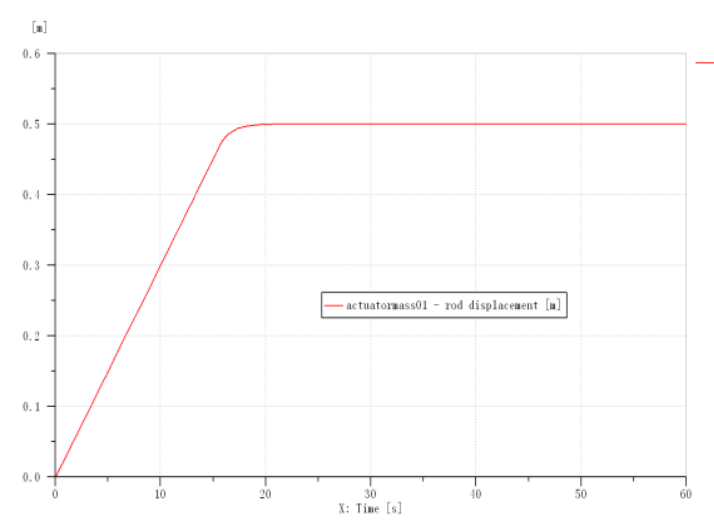

Figure 11 (a). Output Displacement of Actuator under Fuzzy PID Control

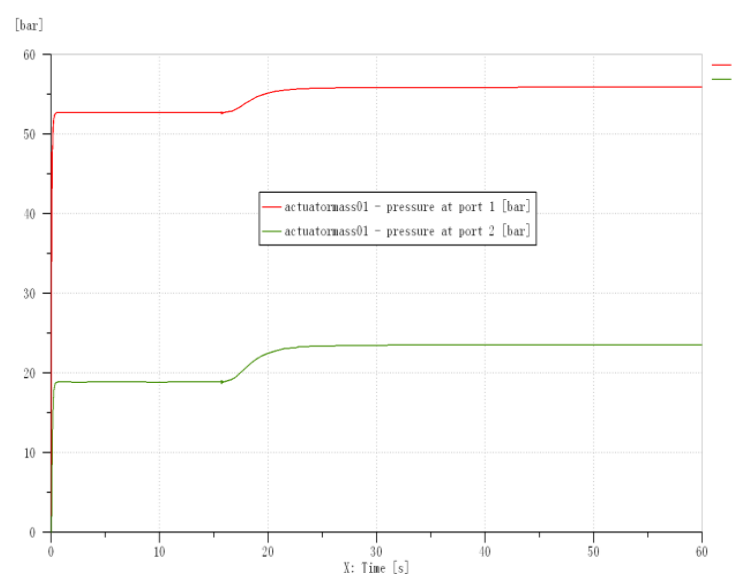

Figure 11 (b). Output Pressure of Actuator under Fuzzy PID Control 


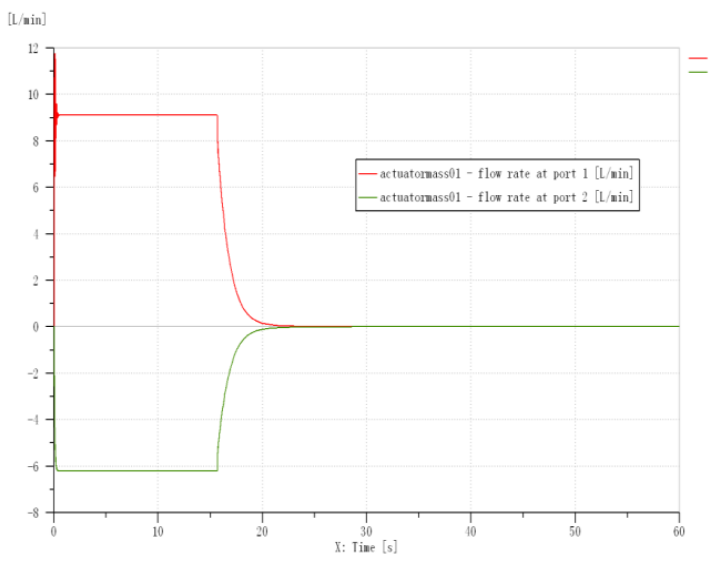

Figure 11 (c). Output Flow of Actuator under Fuzzy PID Control

\section{Conclusions}

1).According to the design and simulation analysis of the hydraulic system model of series hydraulic mechanical arm shows that the plan of structure design of system is reasonable and stability, the characteristic of displacement, pressure and flow could meet the operational requirements of the system.

2).After adding the fuzzy PID control algorithm, the response speed of the system is improved significantly, the response time is shortened greatly, position tracking error is less than $0.1 \%$, and the stability is better, no overshoot and oscillation; At the same time, the fuzzy PID could well correct the input of system and make parameter self-tuning, and also could obtain the PID parameters after optimization, response fast, has a flexible character of control and strong adaptability.

3).Co-simulation of AMESim and Simulink, it's a good use of the advantages for AMESim to facilitate modeling, and Simulink Solves the problems that the electro-hydraulic valve is difficult to carry out the control of fuzzy PID in AMESim.

However, the scope of research object for this study is relatively narrow, the control system is suitable for multi valve control system and nonlinear system only, and the research parameters and environment are relatively ideal. The dynamic and error is smaller than the actual system, therefore, the system will be tested in the later stage.

\section{Acknowledgement}

This work is supported by Natural Science Foundation of Hubei Province (No. 2014CF A528 and No. 2014CFB598), the Education Department Project of Hubei Province (No. D20151406).

\section{References}

[1] S.-Z. Yang and K.-C. Yang, "Basic Mechanic Engineering Control", Huazhong University of Science and Technology Press, Wuhan, (2005).

[2] LI Hongreng, "Hydraulic control system", The defense industry press, (1981).

[3] L.-L. Jiang and J.-J. Zhang, "The dynamic characteristics of hydraulic position servo system based on AMESim simulation", Journal of mechanical engineering and automation, vol. 1, (2007), pp. 35-37.

[4] F. Tian and B.-Q. Jin, "The electro-hydraulic system based on joint simulation of fuzzy PID control research", Pneumatic Hydraulic and Seal, vol. 6, (2010), pp. 27-31.

[5] D.-D. Zhang, Y.-L. Xue and X.-Y. Hu, "Study on the flaw recognition algorithm based on neural network", Information Technology Journal, vol. 12, no. 23, (2013), pp. 7270-7274.

[6] L. Lou, F.-Y. Yang and S. Wang, "Fuzzy PID Control of Electro-hydraulic Servo Systems", Pneumatic and Hydraulic, vol. 7, (2009), pp. 52-54.

[7] K.-L. Xing, Y. Fang and Q. Li. "Simulation of Electro-hydraulic Servo System Based on 
AMESim/Matlab”, Machine Tool \& Hydraulics, no. 10, (2004).

[8] J.-S. Qin and S.-L. You, "Characteristics and application of AMESim software", Journal of mechanical engineering, vol. 12, (2004), pp. 6-8.

[9] G.-M. CHEN, "By modeling and simulation of Matlab", Science press, Beijing, (2002).

[10] Y._F. Mai and Q. Cheng, "Hydraulic Position Servo System Simulation Based on AMESim/Simulink", Mechanical Engineering \& Automation, vol. 2, (2015), pp. 59-61.

[11] J. Li and W.-H. Deng, "Application and Simulation Technology of AMESim and MATLAB/Simulink", Journal of intelligence command and control system and simulation technology, vol. 5, (2004), pp. 61-64.

[12] Q. Luo, M.-X. Huang and Y.-H. Guo, "Simulation and Application Based on Fuzzy Active Control", Electric Drive, vol. 45, no. 2, (2015).

[13] X.-Y. Hu, D.-D. Zhang, G.-Y. Yang and Q. Wang, "Research on the Inverse Kinematics for5R Manipulatorand its Implementation Based on FPGA", Journal of Theoretical and Applied Information Technology, vol. 47, no. 2, (2013), pp. 616-621.

[14] D.-D. Zhang and Y.-Z. Li, "Research on inverse kinematics program optimization of 6R decoupled robot", Sensors and Transducers, vol. 164, no. 2, (2014), pp. 295-301.

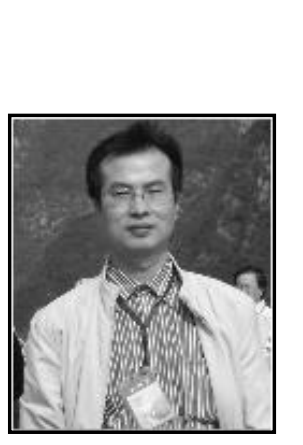

\begin{abstract}
Authors
Zhang Daode, Male, born in 1973, Ph.D. Professor, Master's tutor; Engaged in the research intelligent control system and machine vision, image processing etc. E-mail: hgzdd@126.com
\end{abstract}

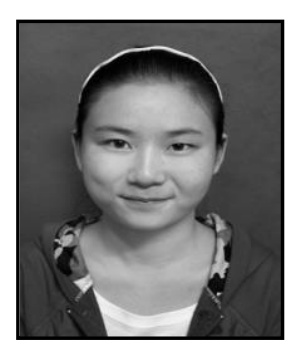

Yan Pian, (Communication): Female, born in 1991, graduate students. Major: mechanical and electronic engineering; Research direction: intelligent control system and hydraulic control system of manipulator.E-mail:368868533@qq.com.

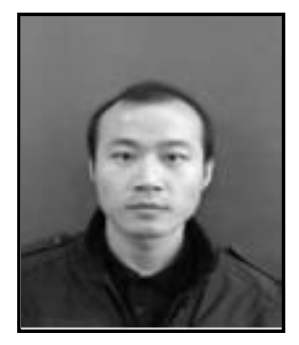

Wang Zhouxing, (Communication): Male, born in 1989, graduate students. Major: mechanical design manufacture and automation. Research direction: intelligent control system and hydraulic control system of manipulator. E-mail:1024948881@qq.com.

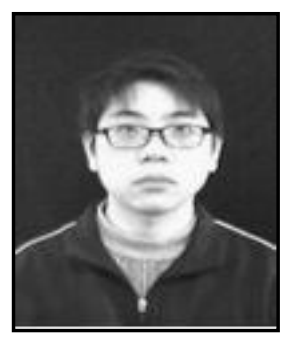

Wu Yuan, (Communication): male, born in 1990, graduate students. Major: mechanical and electronic engineering; Research direction: intelligent control system and hydraulic control system of manipulator. E-mail:wuyuanmm1990@126.com. 